\title{
Witches, Pumpkins, and Other Frightful Topics
}

\author{
By Eric Hollander, MD
}

October brings us Halloween and this month's CNS Spectrums brings us an assortment of frightful topics. These range from suicidality in obsessive-compulsive disorder (OCD); the complex presentation of pediatric bipolar disorder with attention-deficit/hyperactivity disor$\operatorname{der}(A D H D)$; mania arising from traumatic brain injury (TBI); and romantic attachment styles in individuals with psychiatric conditions.

Patients with OCD are usually considered at low risk for suicide, but recent findings are inconsistent. Albina Rodrigues Torres, MD, PhD, and colleagues studied the prevalence of suicidal thoughts and attempts in OCD patients, and compared those with and without suicidality on demographic and clinical variables. Seventy percent reported having already thought that life was not worth living, $56 \%$ had wished to be dead, $46 \%$ had suicidal ideation, $20 \%$ had made suicidal plans, and $10 \%$ had already attempted suicide. Current suicidal ideation occurred in $14 \%$ of the sample and was associated with greater OCD severity. Previous suicidal thoughts were associated with greater depression. Clearly, suicidality has been underestimated in OCD, should be screened for in every patient, and preventive measures undertaken when uncovered. It is important to realize that OCD patients can suffer from impulsivity, depression, and suicide, and are not all risk aversive or harm avoidant.

Secondary mania develops in as many as $9 \%$ of persons with TBI. Furthermore, the treatment of posttraumatic mania is not well defined, and treatments approved for idiopathic mania may not be well suited for use among individuals with TBI. Atypical antipsychotics are indicated for the treatment of bipolar disorder and have been used for other purposes in patients with posttraumatic neuropsychiatric disturbances. Timothy J. Oster, MD, and colleagues report on the first description of the treatment of posttraumatic mania using quetiapine. Beneficial effects on posttraumatic mania, cognitive impairments, and functional disability in the subacute postinjury period are described by the authors. TBI is becoming a growing problem among military personnel returning from Iraq and Afghanistan. There is also a problem due to civilian causes, such as football injuries or motor vehicle accidents. As such, a better understanding of the psychiatric sequela, such as affective instability, and their treatment, are necessary.

Juvenile bipolar disorder (JBD) is a highly impairing chronic mental health condition that affects children and adolescents' overall functioning. Comorbidity with ADHD is extremely prevalent and might determine worse response to treatment. Few studies address the use of atypicals in JBD, although several guidelines suggest their use. Silzá Tramontina, MD, and colleagues conducted a 6-week open trial with aripiprazole in 10 children and adolescents with JBD comorbid with ADHD. Significant improvement in global functioning scores, manic symptoms, and ADHD symptoms were detected. However, significant weight gain was seen, and neither JBD nor ADHD symptom remission was observed in most of the cases. Recent surveys suggest a huge increase in such patients, and a debate rages about whether this is due to ascertainment bias, expansion of the diagnoses, greater screening, or medicalization of adolescence. Nevertheless, these patients are a great challenge to families and clinicians. More studies of the risks and benefits of treatment in this population are sorely needed.

Dr. Hollander is the editor of this journal, Esther and Joseph Klingenstein Professor and Chairman of Psychiatry at the Mount Sinai School of Medicine, and director of the Seaver and New York Autism Center of Excellence in New York City. 
Finally, romantic attachment is the establishment of a relationship with a partner, and is strongly influenced by the individual's attachment style. While several studies have shown that attachment style may contribute to the development of psychopathology, less information is available for romantic attachment. Donatella Marazziti, MD, and colleagues compared romantic attachment styles among patients with different mood and anxiety disorders and control subjects using the Experiences in Close Relationships questionnaire. The secure attachment style was more frequent in the control group, while the preoccupied style prevailed among the patients, with no difference among the diagnostic categories. Patients with different psychiatric disorders were characterized by higher scores on the Experiences in Close Relationships anxiety and the avoidance scales.

Psychiatry can learn much from our colleagues in social psychology and social-emotional neuroscience. Such insights can give us deeper level of understanding about our patients and their relationships, romantic and otherwise, with significant others.

Also in this month's issue, we introduce a new section: In Session. This interview series, conducted by Norman Sussman, MD, profiles clinicians and researchers in the field of neuropsychiatry. The first interview is with Jeffrey $A$. Lieberman, MD, the Lawrence E. Kolb Chairman of Psychiatry at Columbia University College of Physicians and Surgeons in New York City. Dr. Lieberman's interview addresses tardive dyskinesia, a neurological side effect associated with chronic antipsychotic administration that affects neuromuscular function.

I am happy to see another letter to editor in this month's Communique section. The authors report on the extended treatment of a woman with severely treatment-resistant bipolar I disorder. They describe the repeated hospitalizations and treatment trials in their patient. Their account will certainly help elucidate the clinical understanding of complex and refractory cases of depression often seen in clinical practice. The steady correspondences submited by our readers are a welcomed addition to CNS Spectrums. Moreover, the feedback we have received means many more letters will appear in future issues. I encourage you to share your valuable experience in all areas of neuroscience.

Happy Halloween. CNS

\title{
Now Available Online at www.cnsspectrums.com CME-ACCREDITED SUPPLEMENT
} An expert review of clinical challenges in psychiatry CME] The Treatment of Acute Agitation in Schizophrenia

\author{
by Joseph Battaglia, MD, Delbert G. Robinson, MD, \\ and Leslie Citrome, MD, MPH
}

To request a published supplement, pleasee-mail ks@mblcommunications.com Supported by an educational grant from Eli Lilly and Company. 


\section{New York City Premiere, One Night Only!}

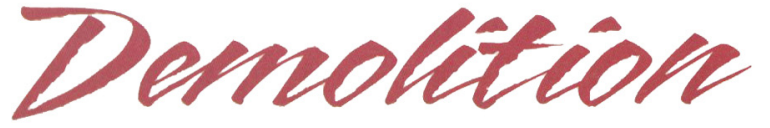

when a mind loses its license to drive

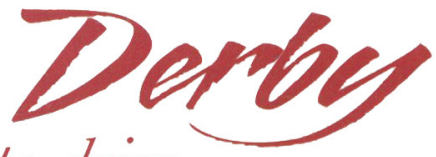

Come experience choreographer Erik Stern's unique, multimedia dance theater performance. For 70 minutes, you will enter the heart, mind, and soul of a son as dementia consumes his parents. Demolition Derby is the perfect metaphor for the scrapes, near misses, and collisions they encounter. The show captures the caregiving experience - the pain, the humor, the moments of physical closeness — using the elegance of dance and music to entertain and inspire. The performance will be followed by a panel discussion where audience members can ask questions of leading experts in Alzheimer's disease and of the performers.

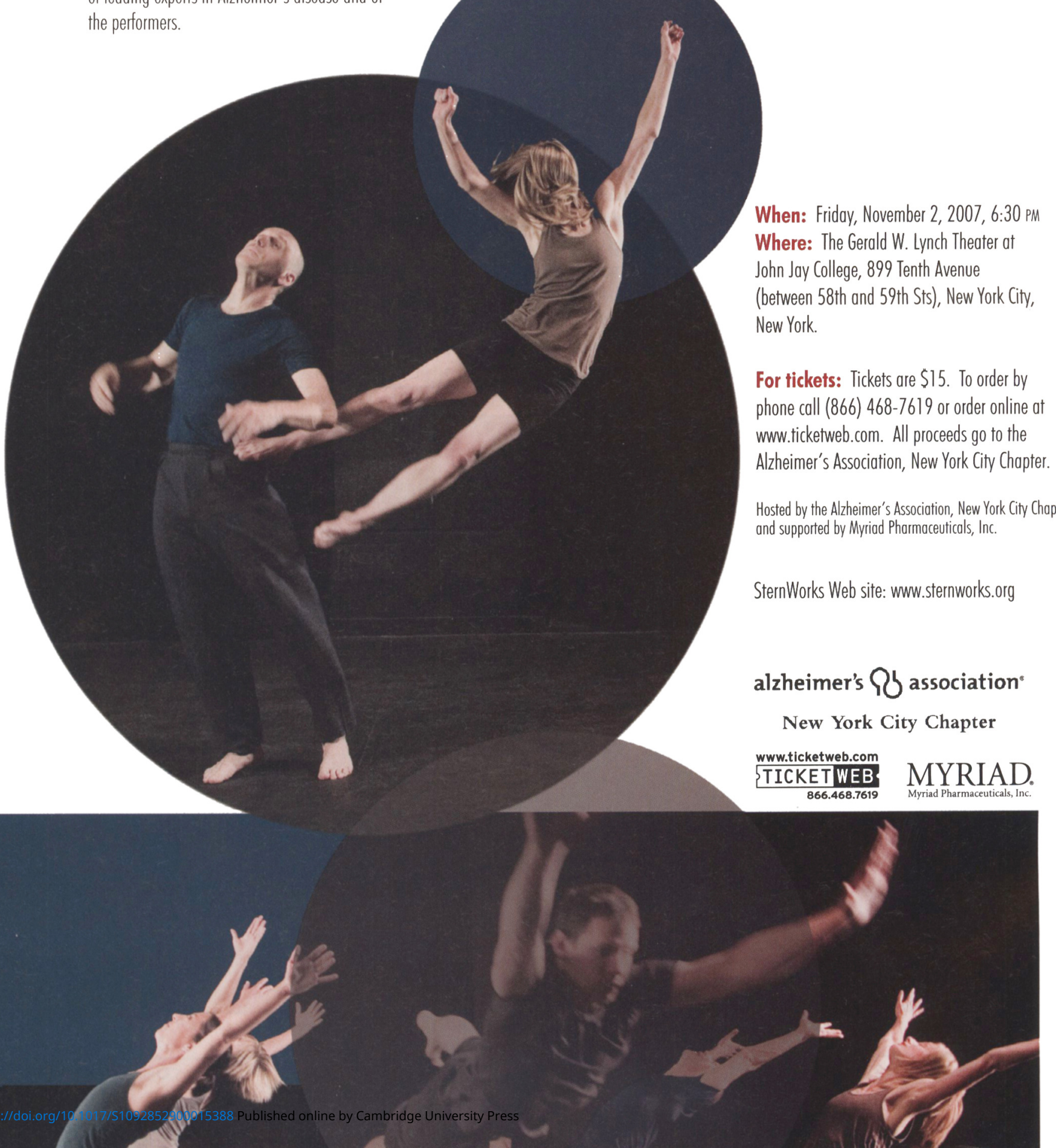

